Association for Information Systems AIS Electronic Library (AISeL)

AMCIS 2001 Proceedings

Americas Conference on Information Systems

(AMCIS)

December 2001

\title{
The Marketing Scale Effectiveness of Virtual Communities
}

Jacques Bughin

McKinsey \& Company

Michael Zeisser

McKinsey \& Company

Follow this and additional works at: http://aisel.aisnet.org/amcis2001

\section{Recommended Citation}

Bughin, Jacques and Zeisser, Michael, "The Marketing Scale Effectiveness of Virtual Communities" (2001). AMCIS 2001 Proceedings. 292.

http://aisel.aisnet.org/amcis2001/292

This material is brought to you by the Americas Conference on Information Systems (AMCIS) at AIS Electronic Library (AISeL). It has been accepted for inclusion in AMCIS 2001 Proceedings by an authorized administrator of AIS Electronic Library (AISeL). For more information, please contact elibrary@aisnet.org. 


\title{
The Marketing Scale EfFectiveness OF VIRTUAL COMMUNITIES
}

\author{
Jacques Bughin \\ McKinsey \& Company, Brussels \\ jacques_bughin@mckinsey.com
}

\author{
Michael Zeisser \\ McKinsey \& Company, New-York \\ michael_zeisser@mckinsey.com
}

\begin{abstract}
Virtual communities have been a prominent business model of the World Wide Web, leveraging the potential of the IP infrastructure to deliver a unique combination of reach and selectivity based on user needs. In a recent paper (Bughin and Hagel, 2000), we argued and provided empirical evidence that virtual communities had witnessed a stronger operational performance than other B2C models in their early stage of development, especially with respect to the building of a franchise (i.e., repeat membership conversion of visitors). In spite of these encouraging results, we also had emphasized that the current profitability of the communities was, however, dramatically negative on average, especially linked to the fact that marketing investments were high relative to the "monetization" potential of the franchise. However, making the model of communities work economically is critical in order to ensure its social viability and autonomy on the web. This paper pushes our early analyses further by investigating economic returns of marketing spent for communities and draws important implications for the business model on the net - in fact, marketing spent has exhibited decreasing returns-to-scale, suggesting that communities should use more of their network effects in order to create more effectiveness and continue to grow as a crucial design model on the internet.
\end{abstract}

Keywords: Communities, marketing scale effectiveness, profitability

\section{Introduction}

The "E-conomy" has exhibited various contrasting pictures lately. While we have been witnessing the sharp decline of the internet stocks, -the natural incubator market of internet stock, the Nasdaq, destroyed value in the range of 3 trillion US Dollars since its March peak of 2000-, we also anticipate in parallel a strong development of internet revenue streams in the full value chain of the E-conomy, from backbone infrastructure, to applications, e- intermediaries and e-commerce, all of which contributed more than USD 600 billion revenue worldwide by mid of 2000 (Internet Indicators, 1999; OECD, 1999).

In the B2C part of this value chain, various business models have contributed to this revenue growth, including the portals (e.g., Yahoo), service providers (e.g.,AOL ), transaction sites (e.g., Amazon or CDnow), or the content providers and virtual communities. ${ }^{1}$ Communities are of particular interest as they best feature the essence of the World Wide Web (Hagel and Amstrong, 1997). However, while providing revenue flow, the recent evidence also shows that most of the B2C sites do not generate profitability, a condition sine qua non for their sustained existence and autonomous influence for the development of the internet - In fact, Bughin and Zeisser (2001), when looking at all pure B2C internet players which went public in the US, show that market places have the best chance to reach profitability, while both transaction sites and content/communities exhibit a very low break-even proportion, less than 5 percent in the IPO sample analysed.

To ensure profitability, content sites and communities imperatively have to significantly reduce their cost exposure, in particular their marketing expenses. In fact, it can be shown that about $60 \%$ of the profitability variance of $\mathrm{B} 2 \mathrm{C}$ sites is linked to the

\footnotetext{
${ }^{1}$ We will use the term 'virtual' and 'on-line' interchangeably in this paper.
} 
difference in marketing costs in total revenue generated. Otherwise stated, marketing effectiveness will be a key driver of breakeven reach and must be monitored closely.

The present article closely looks at this issue and demonstrates that communities are no exception among B2C models in exhibiting decreasing returns-to-scale in marketing. However, the strong membership franchise of the community should be used as a clear means to better marketing effectiveness, and hopefully one of the many paths used by communities to strive quickly towards profitability.

\section{On-Line Communities' Marketing Scale Effectiveness}

In order to fully analyze marketing effectiveness, data must be collected along the complete funnel of customer acquisition , member conversion, member retention, and "monetization". This may appear a significant challenge given the relative absence of data at that level of detail. Nevertheless, in an early paper, Bughin and Hagel (2000) described the 'e-performance' line of McKinsey, precisely aimed at measuring detailed effectiveness of B2C internet companies along that funnel .

This article leverages those data. The survey has been launched since 1999, and now includes its fourth round of data collection for a sample of more of 300 companies worldwide. In addition, data collection is harmonized and includes a consistent time frame (all data were monthly), so as to ensure adequate comparison. Based on those unique (yet firm-level confidential) data, we first provide statistics on the funnel performance, and hence update Bughin and Hagel (2000) to include a much larger sample and an extensive time series of more than 2 years of data (i.e., $50 \%$ of average year of the internet companies in the sample). We then analyze marketing effectiveness through regression techniques, as a way to test the current prevalence (or rather, the absence) of economies-of-scale in marketing spent.

\section{Funnel Capabilities}

One key aspect of on-line companies in their early stage of development is to be able to generate traffic. But of equal importance is to convert traffic into members/customers and retain them to build a strong franchise for revenue and profitability building. In the off-line world, repeat customers make the bulk of money for a company. This trend is likely to be exacerbated on the World Wide Web, because Internet users can browse and shift from one site to another with a simple mouse click.

Data from research company Forrester, have been quoted to show that for B2C transaction sites, only between 2 to 3 percent of on-line site visitors are converted into repeat customers in this early stage of development on the Internet. The 'E-performance' data confirm those rough data, but demonstrate also that conversion capabilities have increased lately, yet remain low at less than 5 percent; since those repeat customers generate up to 45 per cent of total e-commerce revenue, the revenue distribution remains rather dependent on a small amount of on-line visitors.

Benchmarking our analyses to virtual community sites, our data reveal that communities score much better than average B2C sites with an average member conversion of about 16 per cent. This conversion success is also maintained in terms of member retention, because as much as 55 per cent of repeat community visitors convert to community members. This is rather quite good news for virtual communities, as it demonstrates the clear value proposition to internet users in being attracted and retained by community sites.

\section{Marketing Scale Effectiveness}

While communities seem to provide a good value proposition to internet users, the reality is, however, that profitability is not truly visible. In fact, none of the communities in our sample is break-even. They realize on average an EBIT (= operating profit divided by revenue) of minus $83 \%$, a large gap indeed. Given the current emphasis of the market on reaching profitability, it is thus a requirement for communities to generate better effectiveness from its member franchise, especially if the community wants to sustain its viability and freedom on the net.

When analyzing the drivers of profitability, marketing spending comes as a key natural suspect, given the public feeling that many "dot coms" spent excessively for brand building. In order to provide a robust analysis of the issue of marketing effectiveness, a statistical analysis has been run which estimates via ordinary least squares regression techniques the elasticity of revenue (R), members $(\mathrm{M})$, visitors $(\mathrm{V})$ with respect to marketing spent (MKT). 
In practice, the models are of the log-log form, -- which allows to directly derive point estimates of those elasticities :

$$
\text { (1): } \quad \log (Z)=a+b \cdot \log (M K T)+u
$$

where: $Z=R, M, V ; a, b$ are parameters to be estimated via ordinary least square techniques; $u$ is a disturbance term, assumed to be normally distributed.

As known, an elasticity parameter measures a percentage change; hence, an elasticity estimate of 0.5 for total marketing spent on revenue means that for each $10 \%$ increase in marketing spent, the community site will bring $5 \%$ more of revenue. Otherwise stated, an elasticity lower than one demonstrates clear diseconomies of scale, possibly linked to low marketing effectiveness.

The least square estimation results, based on (1) are shown in Table 1 below, for the full sample of communities in the Eperformance line. We also have included dummy variables in the equation in order to account for the different geographies (read continents) of the communities in the sample. The regressions demonstrate a quite good fit, with adjusted R-squares explaining at least $50 \%$ of the variance in each equation.

In terms of economic results, the dummy on the US tends to be statistically significant as a possible reflection that the US is more advanced than other markets (a positive dummy means that the US shifts up the log-log from). But more crucially, the elasticity estimates attached to the marketing spent variable clearly demonstrate that:

(i) diseconomies-of-scale are visible all along the funnel;

(ii) diseconomies tend to decrease in the funnel (with point estimate of elasticity increasing from visitors $(0,72)$ to repeat members $(0.84))$, but

(iii decreasing sharply afterwards in terms of revenue generation, with diseconomies of scale being $50 \%$ of constant returns-toscale.

Table 1. Marketing Effectiveness - Virtual Communities

\begin{tabular}{|lccccc|}
\hline \multicolumn{1}{|c}{ Variable } & Visitors & Repeat Visitors & Members & Repeat Members & Revenue \\
\hline Dummy Europe* & n.s.*** & n.s. & n.s. & n.s. & -0.35 \\
Dummy Asia* & n.s. & n.s. & n.s. & n.s. & -0.91 \\
Dummy US* & 0.33 & 0.12 & n.s. & n.s. & 0.23 \\
Marketing Spent** & 0.72 & 0.72 & 0.74 & 0.81 & 0.51 \\
\hline R-square & 0.73 & 0.54 & 0.58 & 0.62 & 0.48 \\
\hline
\end{tabular}

$*$ dummy $=1$ if community originates from specified continent

$* *$ total value spent

$* * *$ not significant at $5 \%$ risk level

\section{Drivers of Marketing Scale Effectiveness}

Given this low scale effectiveness, it is also worthwhile to identify best practices in marketing effectiveness.

Further experiments based on available data were conducted in order to identify possible best practices. Technically, we estimated the model (1) again, after substituting equation (2) below:

\section{(2): $\quad b=b 0+b 1 . C K N O W+$ b2. LOYALTY + b3.REFERENCE + b4. STICKINESS + b5. CRM + v}

where: all "b" are to be estimated, CKNOW is a dummy $=1$ if the community tracks members subscription; LOYALTY is a dummy $=1$ if the community has set up a loyalty program, REFERENCE is a dummy $=1$ if the community has developed a referential program, STICKINESS is a dummy $=1$ if the number of page views per repeat member is above sample average; CRM is a dummy $=1$ if the community has invested in Customer Relationship Management software. We expect all "b"s to be positive, i.e, they improve marketing effectiveness . 
The estimation is only run concerning the revenue elasticity and is described in Table $\mathbf{2}$ below:

Table 2 . Marketing Effectiveness Drivers-Virtual Communities

\begin{tabular}{|l|c|}
\hline \multicolumn{1}{|c|}{ Variable } & Revenue \\
\hline Constant (b0)* $^{*}$ & 0.42 \\
CKNOW* $^{*}$ & N.sn \\
LOYALTY* $^{*}$ & 0.22 \\
REFERENCE & 0.14 \\
STICKINESS & -0.17 \\
CRM & 0.69 \\
R-Square & \\
\hline
\end{tabular}

*not significant at $5 \%$ risk level

The findings are very interesting in that:

(i) CKNOW, REFERENCES, STICKINESS are all variables linked to a community's established franchise. All of them also significantly improve marketing scale effectiveness, -- especially REFERENCE with an elasticity contribution of 0,22. Summing all those variables, the elasticity contribution is about 0,46 or roughly half way to constant returns-to-scale;. In other words, capitalization on franchise will be an important route for larger (mostly ad support-based) monetization;

(ii) LOYALTY and CRM do not improve marketing effectiveness-a fortiori, CRM programs are negatively correlated with revenue-elasticity, tending to suggest that CRM programs have adverse effects of revenue/marketing ratios of communities.

(iii) In general, even in the best cases, (say, a company with CKNOW, REFERENCES, STICKINESS, but no CRM), the marketing-revenue elasticity is slightly below one. This means that, globally speaking, marketing expenses have not been matched by revenue increase, meaning that marketing budgets have automatically increased the profit gap for communities, --a sure symptom of possible over-investment in marketing spent for the average company in the e-performance sample.

\section{Conclusions}

On-line communities are clearly a critical model of the World Wide Web, which combines unique reach and selectivity. The model, however, currently suffers from very low profitability, especially linked to the fact that marketing investments were high relative to the ad-support "monetization" potential of the franchise. However, making the model of communities work economically is critical in order to ensure its social viability and autonomy on the web. This paper confirms the intuition that marketing spent for building communities has exhibited decreasing returns-to-scale, but also suggests that communities should leverage more of their network effects in order to create more effectiveness and continue to grow as a crucial design model on the internet. As the recent capital market downturns indicate, communities cannot only be a technological feasibility on the net, but must become an economic reality. Learning must come fast in order to keep up with value creation expectations, and for communities to preserve their autonomy on the World Wide Web.

\section{References}

Bughin, J., and Hagel, J. 2000, “The operational performance of virtual communities”, International Journal of Electronic Markets and Business Media, Dec.

Bughin, J. and Zeisser, M. 2001, “From birth to Adolescence-Lessons Learned from On-line Media”, McKinsey Digital Economy $L a b$, in preparation for the McKinsey Quarterly.

Hagel, J. and Armstrong, A., 1997, Net Gain: Expanding Markets through Virtual Communities, Boston: Harvard Business School Press.

Internet Indicators, 1999, University of Texas at Austin, sponsored by Cisco.

OECD, 1999, 'The Economic and Social Impact of Electronic Commerce', Preliminary Findings and Research Agenda, OECD Press. 